\title{
Temporal trend of the proportion of patients presenting with advanced HIV in French Guiana: stuck on the asymptote?
}

\author{
Mathieu Nacher ${ }^{1,2^{*}}$ (]) Florence Huber ${ }^{2}$, Leila Adriouch ${ }^{2}$, Félix Djossou ${ }^{3}$, Antoine Adenis ${ }^{1}$ and Pierre Couppié ${ }^{4}$
}

\begin{abstract}
Objective: In French Guiana, the French territory with the most preoccupying HIV epidemic, there have been great efforts to intensify and diversify HIV testing strategies. The aim of the present study was to review the temporal trends of patients diagnosed with advanced HIV disease in French Guiana. Data trends from the HIV cohort of French Guiana between 1996 and 2016 were thus analyzed.

Results: The proportion of patients diagnosed with advanced disease did not decline over time. Males had lower CD4 counts at the time of diagnosis and there was a plateau for both males (around 40\%) and females (around 25\%) with no apparent reduction of the proportion of advanced disease. Older age groups and migrants presented more often with advanced disease. By contrast, the proportion of patients diagnosed with stage B and $C$ disease declined over time and the CD4 count at antiretroviral initiation and the CD4 nadir increased over time. Despite some progress, the group of patients with advanced disease reached a plateau around $30 \%$ suggesting this particular group still has epidemiological importance in driving the epidemic and in fueling morbidity and mortality, and thus remains a challenge for testing strategies.
\end{abstract}

Keywords: HIV, Advanced disease, CD4, AIDS, French Guiana

\section{Introduction}

Since the first description of AIDS in 1981, the HIV epidemic has generated unprecedented progress in the development of effective drugs and therapeutic strategies. If every single patient was effectively treated, the ambition of a world without HIV would even be theoretically possible [1]. However, in real life, those who are infected and undiagnosed contribute disproportionally to the epidemic dynamics. A major goal is thus to continually reduce the proportion of undiagnosed HIV infections and to treat all HIV-infected patients in order to reduce morbidity and transmission.

French Guiana is the French territory with the most preoccupying HIV epidemic [2]. This French territory has access to all the newest antiretroviral drugs, PreP,

\footnotetext{
*Correspondence: mathieu.nacher66@gmail.com

${ }^{1}$ Centre d'Investigation Clinique, CIC Inserm 1424, Cayenne Hospital, rue des Flamboyant, BP 6006, 97306 Cayenne Cedex, French Guiana

Full list of author information is available at the end of the article
}

residence permits and free universal health care for all HIV patients. About $75 \%$ of persons living with HIV are foreign nationals. The epidemic is driven by sex work, crack cocaine use, and multiple concurrent sexual partnerships [2]. The prevalence among pregnant women has been over $1 \%$ for 2 decades.

In French Guiana, males, older age groups and migrants were tested later on average than other groups [3]. In the past 5 years, there has been a great diversification of HIV testing strategies with ELISA lab testing, testing in emergency services, rapid testing at private practitioners, community based testing, mobile testing centers, and self testing [4]. The number of tests performed in French Guiana is also very high, more than twice of what is performed in Mainland France (205 tests per 1000 inhabitants versus 81 tests per 1000 inhabitants, respectively) [5].

Given the great efforts put into this strategic objective, the aim of the present study was to review the temporal 
trends of patients diagnosed with advanced HIV disease [6] in French Guiana.

\section{Main text Methods}

Data on HIV patients in French Guiana has been available since 1989. Clinical, biological and epidemiological data was entered by specific trained research technicians in the DMI2 government software until 2008, and in eNADIS/DATAIDS since then, as described elsewhere $[7,8]$. The data was aggregated by year. Given the small number of patients in the early years, this led to large fluctuations between years. Therefore, to avoid this "noise" we limited our analysis to the 1996-2016 period. This allowed us to obtain, for each year, the proportion of patients by CD4 count strata at the time of diagnosis, by CDC stage, by CD4 count strata at the time of treatment initiation, and the nadir CD4 count. This was stratified by sex, age group, and foreign/French status.

\section{Statistical analysis}

The main definition of "advanced disease" used was having CD4 counts $<200 / \mathrm{mm}^{3}$. To be more thorough we also looked at the CDC stage, the CD4 nadir, the CD4 count at the time of treatment initiation.

The data was plotted. In order to test for statistical trend in the curves we used regression models regressing the dependent variable on time, in practice testing the hypothesis that the slope in time was 0 . The dependent variables were normalized when necessary to ensure homoscedasticity. Data was analyzed using STATA 13 software (College Station, Texas, USA).

\section{Ethical and regulatory aspects}

Patients included in the FHDH give written informed consent for the use of their data for research and publication of research results. Their identity is encrypted before sending the data to the Institut National de la Recherche Médicale (INSERM), which centralizes data from Regional Coordination for the fight against HIV (COREVIH) throughout France. This cohort has been approved since November 27th 1991 by the Commission Nationale Informatique et Libertés (CNIL) and has led to numerous international scientific publications.

\section{Results}

Overall, between 1996 and 2016, there were 1965 patients analyzed (1053 females and 912 males). The transmission route was heterosexual contact for $86.8 \%$, homosexual or bisexual contact for $3.7 \%$, mother to child for $2.2 \%$ unknown for $6.6 \%$ and other transmission modes were $<1 \%$.

Figure 1 shows that the proportion of patients diagnosed with advanced disease $\left(C D 4>200 / \mathrm{mm}^{3}\right)$ did not decline over time. The linear regression model confirmed that there was no relation between time and the proportion of patients diagnosed with less than $200 \mathrm{CD} 4$ lymphocytes per $\mathrm{mm}^{3}$ (Beta coefficient $=0.09, \mathrm{p}=0.75$ ). Similarly those with less than 50 CD4 lymphocytes per $\mathrm{mm}^{3}$ did not vary with time (Beta coefficient $=0.2$,

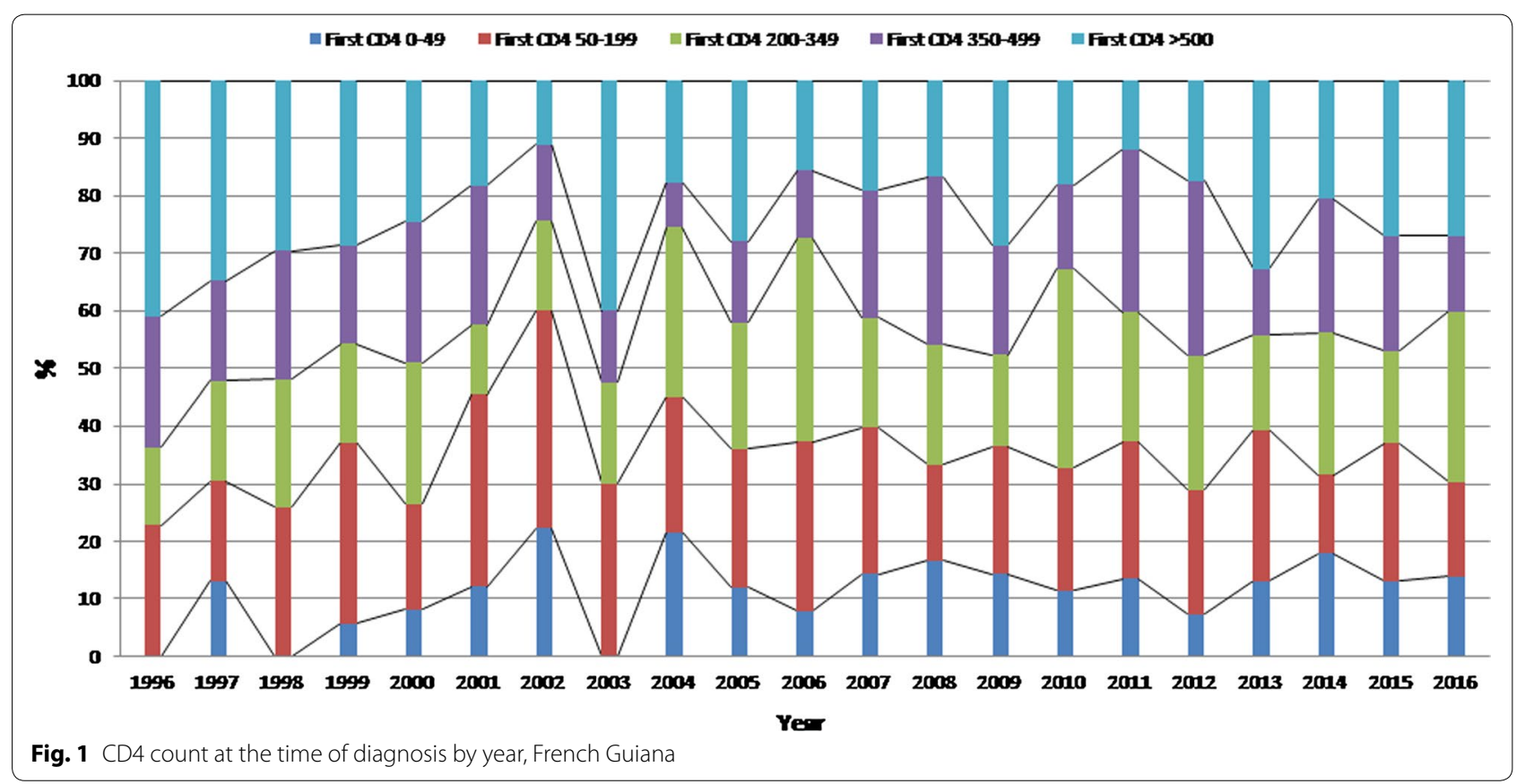


$\mathrm{p}=0.6$ ). The apparent increase in the proportion of advanced disease until 2002 presumably reflects the recent history of the epidemic. Additional file 1: Figure $\mathrm{S} 1$ showed that males had lower CD4 counts at the time of diagnosis but that there was a plateau for both males (around 40\%) and females (around 25\%) with no apparent reduction of the proportion of those with CD4 count $<200 / \mathrm{mm}^{3}$ (Beta coefficient $=0.06, \mathrm{p}=0.88$ and Beta coefficient $=-0.09, \mathrm{p}=0.8$, respectively). Additional file 2: Figure S2 showed that older age groups presented more often with advanced disease. Given the stratification it was difficult to observe any significant trend. Additional file 3: Figure S3 showed that foreign patients were mostly involved in patients with advanced disease. The temporal trend analysis showed that foreign patients became more represented among patients with CD4 counts $<200 / \mathrm{mm}^{3}$ (Beta coefficient $=0.8$, $\mathrm{p}=0.03$ ). Figure 2 showed that over time the proportion of patients first diagnosed with $\mathrm{CDC}$ stage $\mathrm{B}$ and $\mathrm{C}$ HIV-infection declined over time. This was confirmed by statistical analyses showing the trend was significant (Beta coefficient $=-1.27, \mathrm{p}<0.0001$ ). Additional file 4: Figure S4 shows that the nadir CD4 count has gradually increased over time. This was confirmed by the linear regression model (Beta coefficient $=8.29, \mathrm{p}<0.0001$ ). The proportion of patients with CD4 count at treatment initiation $<200$ seemed to have slightly decreased (Beta coefficient $=-0.88, \mathrm{p}=0.003$ ) but not those with $\mathrm{CD} 4$ counts $<50$ at treatment initiation (Beta coefficient $=0.5$, $\mathrm{p}=0.8)($ Fig. 3).

\section{Discussion}

One of the objectives of the French Strategic National HIV/AIDS plan was to reduce by half the proportion of patients discovering their HIV diagnosis at the AIDS stage [9]. The new French National Strategy for Sexual Health now incremented HIV objectives from 90/90/90 to $95 / 95 / 95$ but historical data suggests that diagnosing $95 \%$ of persons living with HIV may be very hard to achieve with the current testing paradigm [10].

The intensification of testing efforts, the multiplication of tools and strategies to enhance early testing, led to disappointing results in French Guiana. Although there has been a gradual decline in the proportion of patients diagnosed at stage $C$, this was not reduced by half as targeted. This objective thus seemed too optimistic. Males, older age groups and foreign nationals were most concerned with advanced disease. One hypothesis for the observed plateau of the proportion of advanced disease may be that given that the majority of patients are immigrants a significant proportion of them may have acquired HIV in their home country and arrive in French Guiana with an "old" HIV infection with significant immune suppression. In this scenario, if the patients were not yet in French Guiana in the early phases, testing them earlier is thus impossible. However, a recent study suggested that most immigrants acquired HIV within French Guiana $[11,12]$. Interventions going towards the vulnerable communities supported by health mediators may lead to some progress in diagnosing persons who would not take the initiative to get tested for HIV. HIV-screening in association

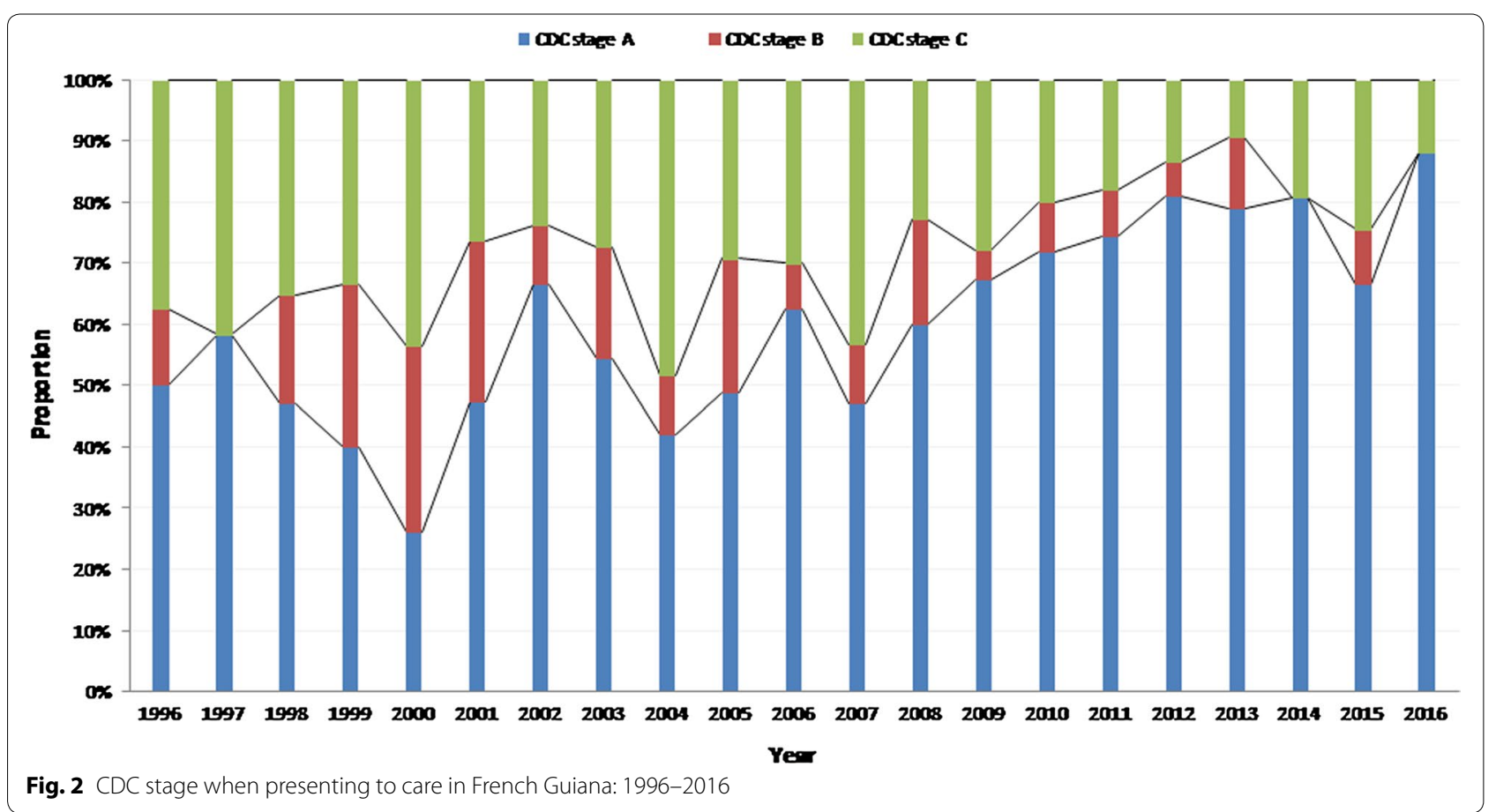




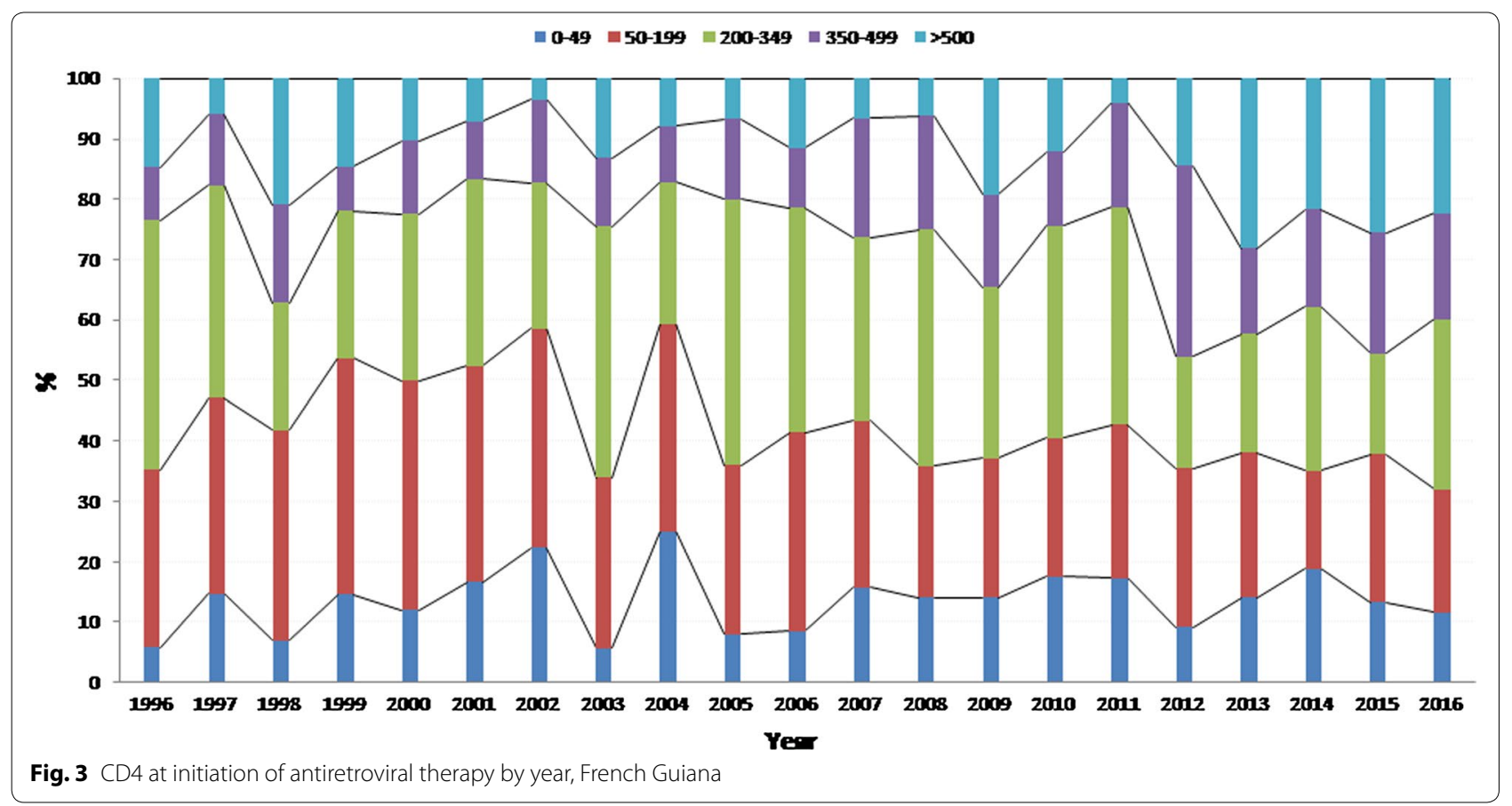

with other health priorities (hypertension, diabetes) may further increase HIV-testing uptake. Finally, studies in France have shown the frequent missed opportunities for HIV-testing of undiagnosed persons reporting frequent contacts with the health system before the diagnosis of HIV is actually performed [13]. Thus every contact with the health system should be an opportunity for testing. However, in practice this is often not done. Perhaps more systematic HIV testing when patients get routine blood examination, with a possibility to opt-out, may lead to a reduction of the proportion of patients with advanced disease $[14,15]$. Much of the population already believes that any blood test goes with an automatic HIV test, which is a reason for erroneously thinking one is HIVnegative and does not need further testing. Therefore, opt-out testing would seem to be easy to implement from the point of view of the population because it would be to implement what many believe is already done. However, the present paradigm for health professionals and Non Government Organizations is opt-in testing and there is still some reticence to shift to a more utilitarian strategy.

Studies in Europe (COHERE, 33 cohorts from across Europe) showed some progress in reducing late presentation of HIV patients, but also showed that it remained a significant problem. In fact when looking at the proportion of patients with late presentation $\left(<350 / \mathrm{mm}^{3}\right)$, with late presentation and advanced disease $(C D 4<200)$, and AIDS, it seemed that between 2006 and 2011 the decline reached a plateau, or was at best very modest [16]. This plateau aspect for advanced disease has also been observed in Sub Saharan Africa [17]. The proportion of patients with advanced disease at the time of diagnosis thus seems to converge to around 30\% (in Greece it seems to have approached $20 \%$ [18]) of the total number of diagnosed patients, despite very different contexts. This sobering observation thus suggests that a significant proportion of persons live for years without knowing their diagnosis and thus continue to contribute disproportionally to the epidemic, and that opportunistic infections still have a bright future despite rapid therapeutic advances. Thus, in any population, there may be groups with different contextual elements, with different psychological attributes which lead to different attitudes towards health, prevention and testing. Some may have difficulties accessing care and some may have no motivation to do so. Whether the prevalence of certain psychological profiles or certain socioeconomic contexts stabilizes to $30 \%$ throughout the world remains to be determined. Reaching this group may be the most important challenge today if we are to have a "French Guiana without AIDS". Indeed, in French Guiana we seem to be stuck around this asymptotic value of $30 \%$ of patients diagnosed with CD 4 counts $<200 / \mathrm{mm}^{3}$.

However, French Guiana is in Latin America where a study in six countries showed there were $55 \%$ of late testers and $45 \%$ of late presenters (CD $4<200)$, so $30 \%$ in that perspective is relatively "good" [19]. In addition, although the CD4 count at the time of diagnosis reached a plateau, the proportion of patients diagnosed because they had clinical signs (stages B and C) declined, therefore 
suggesting that improvements were made to test patients with clinically suspected immunosuppression. The challenge thus seemed to be those who were not clinically patent perhaps because they are less likely to come in contact with the health system.

Regarding CD4 count at antiretroviral initiation, between 30 and $40 \%$ on patients initiated ARVs with CD4 counts below 200 whereas in other parts of Latin America between 50 and $80 \%$ of patients have CD4 counts below 200 when starting ARVs [19]. This may have resulted from a combination of earlier diagnosis and broader antiretroviral treatment indications. The Nadir CD4 count showed a gradual increase, presumably resulting from a combination of scaling up of antiretroviral treatment and perhaps some overall progress in testing patients earlier.

In conclusion, despite efforts to intensify and diversify HIV testing, advanced disease remains a significant problem in French Guiana. Moreover, the proportion of patients with CD4 counts below $50 / \mathrm{mm}^{3}$ also remained constant. Thus, these patients who are long unaware of their diagnosis are presumably key in the propagation of the epidemic and also represent the group with the highest morbidity and mortality rates. In this context, opportunistic infections still have a bright future [7]. This observation challenges our current HIV testing strategies which fail to make progress in this group. Further studies should better describe circumstances and/or traits that underpin this observation.

\section{Limitations}

These data show historical trends in French Guiana and some of the explanatory variables. However, these measures may be crude reflections of real life situation. In addition, the present results may not be easy to translate into optimal operational guidelines to reduce advanced disease. There is a definite lack of qualitative analysis of the stories behind each individual patient diagnosed with advanced HIV disease. These insights would be precious to better understand the trajectories, the missed opportunities, and potential avenues for reducing the frequency late diagnoses.

\section{Additional files}

Additional file 1: Figure S1. Advanced HIV by sex French Guiana: 1996-2016.

Additional file 2: Figure S2. Advanced HIV by age group French Guiana: 1996-2016.

Additional file 3: Figure S3. Proportion of patients with advanced disease by foreign status.

Additional file 4: Figure S4. Nadir of CD4 count by year in French Guiana.
Abbreviations

AIDS: acquired immuno deficiency syndrome; ARV: antiretroviral; CNIL: Commission Nationale Informatique et Libertés; INSERM: Institut National de la Santé et de la Recherche Médicale; HIV: human immunodeficiency virus.

\section{Authors' contributions}

MN conceived the study, analyzed the data, and wrote the first draft; FH, LA, FD, AA, PC included patients, acquired data, and critically reviewed the analysis and the manuscript. All authors read and approved the final manuscript.

\section{Author details \\ ${ }^{1}$ Centre d'Investigation Clinique, CIC Inserm 1424, Cayenne Hospital, rue des Flamboyant, BP 6006, 97306 Cayenne Cedex, French Guiana. ${ }^{2}$ COREVIH Guy- ane, Cayenne Hospital, rue des Flamboyant, BP 6006, 97306 Cayenne Cedex, French Guiana. ${ }^{3}$ Service des Maladies Infectieuses et Tropicales, Cayenne Hospital, rue des Flamboyant, BP 6006, 97306 Cayenne Cedex, French Guiana. ${ }^{4}$ Service de Dermatologie, Cayenne Hospital, rue des Flamboyant, BP 6006, 97306 Cayenne Cedex, French Guiana.}

\section{Acknowledgements}

We thank the clinical research technicians Ketty Bienvenu, Lidia Saint Louis, Sergine Soyon, and Karine Verin.

\section{Competing interests}

The authors declare that they have no competing interests.

\section{Availability of data and materials}

The anonymized data may be made available but this would require permission from the Commission Nationale Informatique et Libertés (CNIL), 3 Place de Fontenoy, 75007 Paris, France.

\section{Consent for publication}

Not applicable.

\section{Ethics approval and consent to participate}

Patients included in the FHDH give written informed consent for the use of their data for research and publication of research results. Their identity is encrypted before sending the data to the Institut National de la Recherche Médicale (INSERM), which centralizes data from Regional Coordination for the fight against HIV (COREVIH) throughout France. This cohort was approved by the Commission Nationale Informatique et Libertés (CNIL) since Nov 27th 1991 and has led to numerous international scientific publications.

\section{Funding}

None declared.

\section{Publisher's Note}

Springer Nature remains neutral with regard to jurisdictional claims in published maps and institutional affiliations.

Received: 13 September 2018 Accepted: 21 November 2018 Published online: 26 November 2018

References

1. Sidibé M, Loures L, Samb B. The UNAIDS 90-90-90 target: a clear choice for ending AIDS and for sustainable health and development. J Int AIDS Soc. 2016;19:21133.

2. Nacher M, Vantilcke V, Parriault M, Van Melle A, Hanf M, Labadie G, Romeo M, Adriouch L, Carles G, Couppié P. What is driving the HIV epidemic in French Guiana? Int J STD AIDS. 2010:21:359-61.

3. Nacher M, El Guedj M, Vaz T, Nasser V, Randrianjohany A, Alvarez F, Sobesky M, Magnien C, Couppié P. Risk factors for late HIV diagnosis in French Guiana. Aids. 2005;19:727-9.

4. Sangare I, Jolivet A, Adenis A, Adriouch L, Levy-loeb M, Dimanche S, Vantilcke V, Marty C, Couppié P, Nacher M. Paid HIV rapid testing in general medicine private practice in French Guiana: a pilot project. Public Health. 2017;151:23-6. 
5. Cazein F, LeStrat Y, Sarr A, Ramus C, Bouche N, Pillonel J, Lot F. Dépistage de l'infection par le VIH en France, 2003-2015. Bull Epidemiol Hebdomadaire. 2016;32:41-2.

6. Antinori A, Coenen T, Costagiola D, Dedes N, Ellefson M, Gatell J, Girardi E, Johnson M, Kirk O, Lundgren J, Mocroft A, D'Arminio Monforte A, Phillips A, Raben D, Rockstroh JK, Sabin C, Sönnerborg A, De Wolf F, European Late Presenter Consensus Working Group. Late presentation of HIV infection: a consensus definition. HIV Med. 2011;12:61-4.

7. Nacher M, Adenis A, Adriouch L, Dufour J, Papot E, Hanf M, Vantilcke V, Calvez M, Aznar C, Carme B. What is AIDS in the Amazon and the Guianas? Establishing the burden of disseminated histoplasmosis. Am J Trop Med Hyg. 2011;84:239-40.

8. Cuzin L, Delpierre C, Yazdanpanah Y, Lert F, Dat'AIDS Cohort. How long do physicians wait to start antiretroviral treatment in newly diagnosed HIV-infected patients? HIV Clin Trials. 2011;12:339-42.

9. Ministère de la Santé. Plan National de lutte contre le VIH et les IST 2010-2014. Paris; 2010.

10. Stratégie Nationale de Santé Sexuelle. http://solidarites-sante.gouv.fr/ IMG/pdf/strategie_nationale_sante_sexuelle.pdf. Accessed 18 Sept 2018.

11. Eubanks A, Parriault MC, Van Melle A, Basurko C, Adriouch L, Cropet C, Nacher M. Factors associated with sexual risk taking behavior by precarious urban migrants in French Guiana. BMC Int Health Hum Rights. 2018;18:24

12. Nacher M, Adriouch L, Van Melle A, Parriault M-C, Adenis A, Couppié P. Country of infection among HIV-infected patients born abroad living in French Guiana. PLOS ONE. 2018;13:e0192564.

13. Champenois K, Cousien A, Cuzin L, Le Vu S, Deuffic-Burban S, Lanoy E, Lacombe K, Patey O, Béchu P, Calvez M. Missed opportunities for HIV testing in newly-HIV-diagnosed patients, a cross sectional study. BMC Infect Dis. 2013;13:200.

14. Galbraith JW, Willig JH, Rodgers JB, Donnelly JP, Westfall AO, Ross-Davis $\mathrm{KL}$, Heath SL. Evolution and escalation of an emergency department routine, opt-out HIV screening and linkage-to-care program. Public Health Rep. 2016;131:96-106.

15. Morlat $P$, editor. Prise en charge médicale des personnes vivant avec le VIH. SIDA CNd ed. Paris; 2018.

16. Mocroft A, Lundgren JD, Sabin ML, Monforte AA, Brockmeyer N, Casabona J, et al. Risk factors and outcomes for late presentation for HIVpositive persons in Europe: results from the collaboration of observational HIV epidemiological research europe study (COHERE). PLoS Med. 2013;10(9): e1001510:1-14.

17. Carmona S, Bor J, Nattey C, Maughan-Brown B, Maskew M, Fox MP, Glencross DK, Ford N, MacLeod WB. Persistent high burden of advanced HIV disease among patients seeking care in South Africa's national HIV program: data from a nationwide laboratory cohort. Clin Infect Dis. 2018;66:S111-7.

18. Metallidis S, Pilalas D, Skoura L, Haidich AB, Tsachouridou O, Papaioannou M, Chrysanthidis T, Bakaimi I, Antoniadou ZA, Margariti A, Malisiovas N, Nikolaidis P. Time trends and correlates of late presentation for HIV care in Northern Greece during the decade 2000 to 2010. J Int AIDS Soc. 2012;15(2):17395

19. Crabtree-Ramírez B, Caro-Vega Y, Shepherd BE, Wehbe F, Cesar C, Cortés C, Padgett D, Koenig S, Gotuzzo E, Cahn P, McGowan C, Masys D, SierraMadero J, CCASAnet Team. Cross-sectional analysis of late HAART initiation in Latin America and the Caribbean: late testers and late presenters. PLOS ONE. 2011;6:e20272.
Ready to submit your research? Choose BMC and benefit from:

- fast, convenient online submission

- thorough peer review by experienced researchers in your field

- rapid publication on acceptance

- support for research data, including large and complex data types

- gold Open Access which fosters wider collaboration and increased citations

- maximum visibility for your research: over 100M website views per year

At BMC, research is always in progress.

Learn more biomedcentral.com/submissions 